\title{
En busca de una (po)ética: Roque Dalton*
}

- Luis Alvarenga

\section{A Carlos Cotto y Alicia Hernández}

Una tarea de importancia capital para El Salvador sería escribir una Historia de las ideas. Como muchos países de América Latina, El Salvador carece de una tradición filosófica arraigada, sobre todo si buscamos autores que hayan legado sistemas de pensamiento, como en la tradición occidental. Las condiciones materiales, las vicisitudes que han tenido que enfrentar las instituciones académicas, y una tradición cultural autoritaria han sido algunos de los frenos de esa actividad filosófica. En vez de sistemas filosóficos, hemos tenido indagaciones sobre la realidad que han venido, en buena parte, de intelectuales cuya actividad central no ha sido la filosofía - al menos explícitamente-. La historia de nuestras ideas sociales, filosóficas y políticas se ha nutrido en alguna medida de la literatura. Cito dos ejemplos, tan disímiles como cercanos: Alberto Masferrer y Roque Dalton. Cercanos, porque ambos partieron de su posición intelectual para cuestionar al sistema social. Disímiles, porque difirieron sensiblemente en su manera de proponer soluciones al drama nacional y porque tanto su visión de mundo como su concepción del trabajo intelectual tienen diferencias muy hondas. Ambas intuiciones de mundo están unidas, empero, por un acendrado humanismo y una preocupación por las mayorías. Pero si algo tienen en común, Masferrer y Dalton, es que son autores de los que se habla mucho, pero se lee poco. La visión ideologizada ha suplantado una lectura crítica de sus textos, y por ello no hemos sido capaces de apreciar la complejidad de su obra intelectual. Dejo para otra ocasión una

* Ponencia presentada ante el Primer Coloquio Internacional de Literatura y Testimonio en América Central. Universidad de El Salvador, marzo de 20()1 
propuesta para la lectura de la obra de Masferrer. En estas líneas, quiero proponer algunos acercamientos al pensamiento de Roque Dalton.

En términos generales, considero que la tentativa de Dalton es hacer coincidir el talante poético con la praxis política y la preocupación ética, es decir —para ocupar una expresión acuñada por Rafael Lara Martínez-: la formulación de una (po)ética. Propongo que en este recorrido por las ideas de Roque, nos detengamos en algunos momentos de su obra poética. Más adelante, haré alguna referencia a sus ensayos dispersos.

Propongo que en este recorrido por las ideas de Roque nos detengamos en algunos momentos de su obra poética. Más adelante, haré alguna referencia también a sus ensayos dispersos.

\section{1 . La formación de la (po)ética}

\subsection{El ofendido toma la palabra}

Hay dos poemarios que preparan el terreno para Taberna y otros lugares, la opera magna de Dalton: El turno del ofendido y Los pequeños infiernos. Antes de ello, está esa hermosa exaltación lírica llamada El mar, construida en amorosa atmósfera. Hay en estos libros un hilo conductor: la distancia como condición necesaria para el surgimiento del poema.

La lejanía del país es la gran ofensa. Es este el turno del débil: «En el caso de los golpes no me hagáis esperar. Comprendo vuestra envidia, pero todo ha sido dispuesto así en discusiones muy antiguas. El dueño de la flaqueza es el encargado de escupir. Y vosotros sois fuertes, fuertes...», dice en uno de los poemas. El país se nos ha alejado también por la falsedad: «Creo que nos han engañado suficientemente.». Pero es terrible la verdad, porque adquirirla implica dolor y la responsabilidad del odiar al prójimo: «Ahora poseo la llave del jeroglífico/ pues me la dio el dolor entre risas de ebrio/ entre escupitajos de carcelero y miradas de perro/ furioso sin piedad (...) Ahora mismo voy a quitar algunos de los últimos velos./ De las heridas/ me haré cargo yo».

Hay otra lejanía — no sólo en ambos libros, sino en toda la obra de Dalton-, la esencial a la condición de la poesía. El poema logra reintegrarnos el instante fugaz con todas sus maravillas. Pero, para eso, es necesario que ese instante ya sea inalcanzable. Las palabras del poemas son el ritual de recuperación poética de ese instante. En estos dos libros confluyen la lejanía del país - ¿acaso su poesía, sus ensayos y su actividad política no corresponden al anhelo de recuperar al lejano El Salvador, a ese que no se sabe si es un país verdadero, o tan sólo un invento? - y la lejanía amorosa. Las palabras del poema, que nos fueron dichas en el supremo instante, son nuestra sed. Intentamos decirlas, recuperarlas de su precariedad e instaurarlas entre nosotros. Pero el poeta no cree en cualquier abolición de la lejanía. Acercarse es acercarnos a la verdad, en vez de 
perpetuar lo falso: «No puedes pasarte la vida volviendo,/ sobre todo a la porquería que tienes por país,/ al desastre en que te han convertido la casa de tus padres,/ sólo por el afán de saludar o traernos palabras de consuelo».

Otra clave en estos dos libros es la posesión de la verdad. Quien la adquiere - cl poeta-, a costa de indecibles suplicios, se vuelve un monstruo a ojos de los demás hombres. Se le repudia, como al personaje de Las cicatrices, porque se sabe que lo que el poeta tiene que decir - la verdad-es doloroso y corroe la vida, o el espejismo de vida, que tenemos.

El secreto de la verdad - secreto del poema- es monstruoso porque nos vuelve más solitarios: «Andaríamos mejor sin estas sombras. Con ellas hay un nombre que no podré enseñaros. Se incendiaría la negrura quemándoos, quemándonos en dura solución de silencio. Y debo confesar/ que ello es alto obstáculo, muro perseverante,/ clima enemigo en la misma fundación de la caminata.» Pero la soledad en sí misma no es una salida: Es la condición de «aptos para ser odiados», de las cicatrices, lo que el poeta se impone para que esta verdad sea trascendente. Es ese «intentarlo todo», para que el amor de los hermanos sea propicio y salvífico. Si esto último recuerda el discurso cristiano, no es antojadizo. Es la idea de salvación por el martirio la que está implícita aquí. La condición poética es una condición martirial: la del que padece por la trascendencia de la verdad.

El poema Arte poética, incluido en El turno del ofendido, es interesante desde el punto de vista de la poética daltoniana. Existe la angustia del individuo, dice el poema, pero están también «los demás hombres» y su esperanza colectiva: «se embriagan como Dios anchamente/ establecen sus puños contra la desesperanza/ sus fuegos vengadores contra el crimen/ su amor de interminables raíces/ contra la atroz guadaña del odio/.» Se plantea, entonces, una interrogante:

La angustia existe sí.

Como la desesperanza

el crimen

o el odio.

¿Para quién deberá ser la voz del poeta?

Es este el dilema de mucha literatura "progresista», que se plantea el tener sentido únicamente si es en función de una colectividad, o de un proceso de transformación social. Pero la voz del poeta, si es grande, abarca esto y lo rebasa. Es importante que la voz del poeta vaya «hacia la persona/ hacia todo el pueblo/ hacia el universo», como dice Silvio Rodríguez. En verdad, Dalton conoce que la grandeza de la literatura reside en eso: en su universalidad, entendida esta como en poder decir algo aquí y ahora, pero también para otros lugares y para otros tiempos. 
El poema que más amo de Dalton está en Los pequeños infiernos, y se llama El hijo pródigo. Dedicado a los poetas cubanos Heberto Padilla y Pablo Armando Fernández, tiene citas de Saint-John Perse y Henri Michaux, que dejan sentada una durrelliana relación de «odio creativo» con el país. Está dividido en dieciocho estancias. Cada una de ellas es un combate que el poeta entabla contra un medio atroz «De ahí surge la terrible situación de tener que rendir culto a la verdad, de profesar su religión», explica el poeta. La verdad es rebeldía ante ese trono en el que «únicamente cabe la mentira». Pero, ¡cuán lejos está el poeta de creer que verdad y rebeldía son, por sí mismas, infalibles!: «Porque conocemos las escaramuzas de toda gran verdad al caer - - xtraviados sus anhelos de altura - en el centro del hormiguero». Deja sentada una actitud crítica que explica mucho:

«Incluso te digo que te cuides de tu rebeldía./ Ella es el mejor corazón,/ pero también es capaz de segregar podredumbre.».

Una actitud semejante implica una enemistad a muerte con el entorno, y por lo tanto, se impone una ruptura:

El tiempo de dormir las joyas con canciones de países lejanos, el tiempo de lavar la piel con esencias por las que hubo de morir una tribu de viejos hábiles, el tiempo de escoger a las mujeres en los primeros meses del año por su olor y los hoyuelos de las rodillas, el tiempo de las mentiras de gala para solaz de los rebaños, el tiempo de la prebenda secreta y los pactos sin castigo. el tiempo de los asnos gordos, -ah lapso de jolgorio!declina.

Es entonces el tiempo de reconocer nuestro verdadero ser:

¿Cuál será nuestro rostro?

No somos hijos de la bella-Reina-de-Mayo nuestra madre castiga sus viejos pechos contra las piedras del rio y aúlla y hiede mostrando su lengua que alcanza hasta los ojos

(desorbitados.

¿Cuál será nuestra heredad?

No somos dueños del lecho en que despierta el maíz nuestra tierra es de piedra y lodo donde no germinan los jóvenes cadáveres hacienda de las culebras cerosas que silban en medio de todas las tormentas que nos empujan al mar.

El poeta, que se siente predestinado para el sacrificio, también dice:

¿Cuál será nuestro destino? 
No somos aspirantes a la vecindad del sol

nos basta cultivarnos para el agrado de los sacerdotes sacrificadores

sabemos que cada una de nuestras venas espera sus cuchillos

y hablamos con satisfacción de la túnica que llevaremos el último día.

La rebeldía empieza con la autenticidad: El silencio ante la gritería dominante: «Por eso es gran crimen llevar el índice a los labios, bajar los ojos, palidecer ante una dulce mirada que sólo quería tener un lugarcito en el recuerdo»; el ser grande en el país para enanos que nos han querido hacer creer que es éste:

Parados frente a mi casa poderosa dirán:

"Qué quiere decir este anciano que sólo conserva juventud para gozar de las frutales mozas que insolenta el invierno?

Bien extraños son sus signos.

Y lo peor es que sólo advertimos su sabor a perturbación.

Creemos sin embargo que ha cometido atentado

contra la misma necesidad de los dioses, contra la omisión del temor en que quedamos

Practicaremos con él la sabiduría de la previsión en la condena:

en nombre de la paz del viudo glotón,

de la fragancia de los abogados y los obispos,

de los sueños de nuestras vírgenes devotas,

del garbo y buen humor de nuestros dorados dirigentes,

de la lucidez de nuestros esbirros, de nuestros juglares,

de nuestros curanderos, de nuestros testigos,

de nuestros cómplices, apañadores, confidentes, déspotas, hacedores de mofa, proxenetas, maricones, usureros, marimachos, envenenadores, (pacificadores, aduladores, loadores de la resignación, sádicos, usadores de cadáveres, reclutadores de insumisos para la muerte, tontos,

retractados, confesos, colegiados, pulcros...»

Pero a mi casa no entrarán sus tropeles.

¿Es esto hacer votos a la soledad?

No temáis por mi y perdonad que me retire por un momento.

Voy a reirme de vosotros.

La risa en Dalton, como ya se ha dicho, es elemento de rebeldía. Pero también de autenticidad, en un medio donde se premia la solemne estupidez. La actitud del poeta es esta: «Inminencia de lo peor. Qué risa de nuevo, qué risa!». El reír en medio de la miseria espiritual. El reír, como producto de asumir la verdad de lo ridículo del entorno: «También esta caída se puede aprovechar. Lo principal no es ser como los peces ciegos que portan los mejores colores. Lo principal no es llamar vino al vino envenenado. Holguemos, cándidos. Digamos

En busco de una (po)ético: Roque Dalion 
hurra en la congregación de los desnudos! Hossana en este valle de saliva!». Quien se tome en serio al entorno opresivo está condenado por cobardía: «Y los demás, lleven sus gestos agrios al cementerio de las hojas, sus caras de uña del siglo!».

Propone una actitud crílica para el país, pero también lanza sus dardos en otra dirección:

Porque,

debeís acaso aceptar que la tierra prometida

también es un enorme mar de estiércol,

que el tiempo prometido transcurrirá

en un enorme mar de estiércol?

Ante la resignación que implica cierto pesimismo, está la siguiente actitud vital:

Pero es que ha pasado la edad de las grandes hazañas?

Vuestros brazos han caido también en la trampa de las lamentaciones?

Es que podríais deponder vuestra raza de cataclismos

por las insinuaciones de una confusión, a lo más, digna del sonrojo?

Sabedlo:

no servis para renegados,

no tenéis el lúgubre, torvo valor de los traidores.

Cualquier señal de asco en torno vuestro os mataría pronto,

después de algunos balbuceos.

Debemos estar más allá de la esperanza para empezar a ser otros, más auténticos, más nosotros. En el terreno de las luchas sociales y en el de la rebelión poética, es esta la actitud de Roque:

No advertís lo aburrida que puede ser la esperanza?

Lo que importa es tomar una decisión:

la del asesino, la del que se atreve al fin a ser él mismo,

la del salvador o la del héroe.

No puedes pasarte la vida volviendo,

sobre todo a la porquería que tienes por pais,

al desastre en que te han convertido la casa de tus padres,

sólo por el afán de saludar o traernos palabras de consuelo.

Toda piedad aqui es cruel si no incendia algo.

Todo signo de madurez debe probar su capacidad de destrucción.

$Y$ no pidas mucha certidumbre. Cuando uno se ahoga

no pregunta a qué puerto va el primer lanchón que pasa.

Pero sobre todas las cosas, la santa, la pura impaciencia. 
Constata el poeta que ganar la autenticidad es empezar, al fin, a ser jóvenes El poema concluye con esta bella admonición:

Mientras tanto no nos limitemos a esperar.

Hemos dicho cosas demasiado graves

para quedarnos impávidos en la súplica de un veredicto.

No estamos solos.

Hay que decir que Los pequeños infiernos aún no ha sido publicado como libro autónomo. La única edición de ese libro, impresa en España por Llibres de la Sinyera -que tenía por consejo editorial a José Agustín Goytisolo, Manuel Vázquez Montalbán y Pere Gimferrer- no es exactamente Los pequeños infiernos. Se trata más bien de una antología con ese nombre, que recoge poemas de El turno del ofendido, Los pequeños infiernos y Taberna y otros lugares. El editor - Goytisolo- no deja constancia de lo anterior. Como ya se ha dicho antes, el prólogo es bastante caricaturesco en cuanto a su visión de Dalton, y no deja de rezumar cierta prepotencia eurocéntrica. Según Luis Suardíaz, Roque no estuvo de acuerdo con esta publicación, pues el libro «aparecía disminuido, desperdigado y sobre todo precedido de una introducción nada bien intencionada (...) Se dolía de la interpretación aparentemente coloquial, y sin embargo cargada de irónico desprecio, en la que el autor de la recopilación revelara a los cultos lectores de la editorial catalana la existencia de un simpático maromero de la poesía, ejemplar capturado en las selvas gastronómicas, en los bosques peligrosísimos de los centros nocturnos, metido hasta los tuétanos en las extrañas luchas de los latinoamericanos»' '. Se hace patente la responsabilidad de publicar la edición íntegra del libro.

\subsection{Taberna: El lugar de los desafios}

Galardonado con el Premio Casa de las Américas en 1969, el libro Taberna y otros lugares ocupa indiscutiblemente un sitio preferencial dentro de la crítica de la obra de Dalıon. No es para menos: en Taberna confluyen los más variados registros culturales con una serie de técnicas literarias, que constituyen, en el caso daltoniano, una auténtica ruptura: un hasta aquí. Rompe -como expresamente lo declara el poeta en entrevista con Mario Benedetti- con la concepción poética de la cual Pablo Neruda es el máximo cultivador: la poesía como canto al universo. Propugna Dalton, entonces, una poesia de ideas. Establece una ruptura con la concepción poética limitada sólo al ámbito de lo emotivo y se embarca en una ambiciosa empresa poética que quiere aprehender, desde su ser poético, la complejidad del ser humano y de la realidad que está transcurriendo. Distingamos en el hacer poético dos elementos: la esfera de las ideas del autor (su Weltanschauung) y cl ámbito de lo propiamente poético. En el buen poeta, lo raigal -incluso en su personalidad, en su quehacer diario- es la actitud poética. Sus ideas sobre el

En busca de una (po)ética: Roque Dalton 
mundo, sobre su sociedad y sobre los seres humanos pueden explicar su producción poética, pero no lo suficientemente. El discurso científico y filosófico pueden explicar mucho, pero hay una vasta zona ante la cual enmudecen: sus categorías resultan insuficientes para dar cuenta de ella. Esa vasta zona, la de la poesía, nutre en el poeta su ser-en-el-mundo y también su comprensión del mismo. Para Dalton, su condición de poeta es radical (está en la raíz de su ser-en-el-mundo). Sus ideas se nutren de esa condición y, en su caso, se tornan elementos poéticos. Pasa lo mismo con su experiencia personal: Dalton habla de sí mismo desde el primero hasta el último libro, pero su tono es más que anecdótico: el testimonio individual se toma una experiencia poetizable, y, en virtud de su actividad y de su ser raigal, una experiencia poética. Mientras las ideas (lo ideológico) estuvieron subordinados al orden poético, Dalton escribió grandes poemas -incluso aquellos de clara intención política: La segura mano de Dios y muchos de El turno del ofendido- Cuando ocurre que el poeta trata de subordinar el texto poético a la idea política, vemos ahí algo que no cuajó, como muchos de sus Poemas clandestinos — no todos, pero sí un número significativo-.

En Taberna y otros lugares hay una manera poética de inteligir la realidad. Para ello, se vale del poema en verso y del poema en prosa, y echa mano a muy variados recursos (y discursos) expresivos. Al igual que Pessoa, hay voces de otros que hablan por su medio. La angustia doble del sobreviviente de la cárcel y del exiliado que no encuentra el hilo de Ariadna conviven dialécticamente con la voz de un contador de desternillantes historias. Especial mención tiene el pocma en prosa Con palabras. Deja ahí sentado un punto de vista sobre el lenguaje, que rebasa lo limitado de la comprensión científica sobre el mismo («uno de los crímenes más abominables de la civilización occidental y la cultura cristiana ha consistido precisamente en convencer a las grandes masas populares de que las palabras sólo son elementos significantes»). Sin decirlo abiertamente, se sitúa también más allá del discurso esotérico (en el que las palabras son mágicas: lo son, pero también son algo más): las palabras tienen poder sobre nosotros: «¿Por qué suena mal una palabra libre de significados tabú si no es por algo intrínseco a clla misma, a su corporeidad, a su ser, que es independiente de su función más común, la cual, por otra parte, no tiene necesariamente que ser la única, ni siquiera la principal?». En virtud de ese poder, las palabras pueden ser liberadoras o no: «Deberíamos recordar lo que le pasó a Stalin por hacer de las palabras excepciones del materialismo dialéctico: de ahí la muerte de Babel, de ahí el naufragio-entre-témpanos de la Internacional, de ahí la prosa soviética contemporánea. Si se le hubiera hecho frente al problema con apasionamiento y coraje, olra y magnífica sería la situación. Habría bastado con comenzar a conocer verdaderamente las palabras, a organizarlas para el porvenir, a discutir con ellas sobre la libertad y, sobre todo, a separarlas de las cuasi-palabras, las anti-palabras, las palabras degencradas». Son, entre otras cosas - y esto lo intuye Daltonlas palabras hacedoras, destructoras y portadoras de visiones de mundo. Tienen

\section{8}

Realidad 81, 2001 
una función ética y cognoscitiva: «y si he perdido el tiempo en declarar estas cosas es porque luego se compruebe que nadie las ha entendido verdaderamente, ha sido en la forma que lo hicieron Jesucristo o Lenin, aceptar lo cual, por lo menos, me hará dormir tranquilamente esta noche».

Es patente la urgencia de un lenguaje emancipador. Roque habla de palabras muertas, palabras que han perdido su vitalidad y que ya no nos dicen nada. Aparentemente estaría la vieja cuestión de las palabras trilladas, etcétera, pero también hay algo muy interesante: la comprensión de que el lenguaje expresa una visión de mundo. Y también que el lenguaje tiene mucho que ver en la formación de ésta. Si la visión de mundo enajenada cambia por una visión de mundo liberadora, ello será en buena medida porque las palabras también han sufrido una modificación. Exhorta Roque a que dialoguemos con las palabras: esto no es otra cosa que un llamado a elaborar una teoría y una praxis que liberen también al lenguaje de su opresión.

Antonio Gramsci sostenía que «sólo la verdad es revolucionaria». Para el poeta salvadoreño, la búsqueda de la verdad —a través de la poesía, del debate intelectual o de la praxis política- es central. Dalton es incapaz de disociar la búsqueda estética de la función ética, que es la búsqueda de la verdad liberadora. «Por eso fui llamado el escrutador, el más apto para ser odiado», dice en Las cicatrices. El escrutador es el buscador y el interrogador de la realidad, que rechaza la belleza convencional, rompe con ella, y busca la verdadera belleza, la que traiga la plenitud humana.

La aprehensión poética de la realidad se expresa en el poema Taberna. La reelaboración de los discursos e intelecciones sobre la realidad socialista y su ordenamiento se hace bajo la visión poética del autor acerca de esas ideas. Es como que si Dalton metabolizara poéticamente lo escuchado en la taberna $U$ Fleku. De ser una «encucsta sociológica furtiva», esto pasó a constituirse en una realidad poética.

\subsection{Poemas clandestinos}

El último libro escrito por Roque, Poemas clandestinos ha sido relegado a priori como el libro de menos calidad de Roque. Es cierto, hasta algún punto: no tiene la belleza de Los testimonios o la complejidad de Taberna. Pero no por ello deja de ser un libro importante: lo es puesto que representa para Roque la resolución de su pugna por hacer de la vida un poema.

La eticidad del poeta es un motivo que salta desde la primera página. La «Declaración de principios» que hace las veces de prólogo sirve para dejar en claro una posición moral: El pocta tendrá legitimidad por cuanto sus acciones estén comprometidas con la revolución social. Las opciones a escoger, para Roque, son ser sirviente, payaso o enemigo. En verdad, se reducirían a dos: ser o no instrumentos de la dominación capitalista. Para redondear el punto y volver sobre lo planteado:

En busca de una (po)ética: Roque Dalton 
el hacer poético tendrá razón de ser si contribuye al proyecto liberador. Tal el planteamiento de Dalton en esta época, que es una radicalización de sus ideas al respecto. Antes, daría la impresión de que es viable ser un poeta honesto, sin tener una participación directa en la lucha social. Ahora eso no basta. Esta evolución no es antojadiza. Recuérdese el contexlo del ascenso de la lucha armada en el país.

Si el deber-ser del poeta se ha radicalizado, también el deber-ser de la poesía deberá sufrir una radicalización. «Poeticus eficacciae»: el poema tiene un sentido pragmático: su eficacia se prueba al subvertir el orden burgués.

En Poemas clandestinos hay una — sin duda que hay otras muchas - idea fundamental: la tentativa expresada por el autor de poner a la poesía en «donde le corresponde»:

Ahora estás en tu lugar:

no eres ya la alternativa espléndida

que me apartaba de mi propio lugar.

El Dalton de esta etapa no le concede autonomía a la creación poética. La pocsía debe estar sujeta a la praxis del autor. Aunque no del todo: Es también un elemento que puede ayudar a la transformación ética del poeta:

Hoy también puedes mejorarme

a)'udarme a servir

en esta larga y dura lucha del pueblo

Vuelve Dalton sobre la estética. Contra el valor intrínseco de la belleza, identifica, nuevamente, la belleza en lo que sirve para la liberación:

Y sigue siendo bella

compañera poesía

entre las bellas armas reales que brillan bajo el sol

entre mis manos o sobre mi espalda.

Como el autor es un revolucionario - lomado este término en el sentido de «buscador de la verdad profunda», desarrollando la frase de Gramsci que citábamos mucho antcs-, el poema deberá serlo también. El poema es visto, ya no como la redondez perfecta, sino como una obra abierta, algo que le de ja con las preguntas para buscar la verdad. Este concepto de obra abierta no es nuevo en Roque: sólo vale recordar Los hongos, y, más acorde a la obra que comentamos, Un libro rojo para Lenin. El poema Recuerdos y preguntas finaliza precisamenle con un cucstionamiento ético:

Oll noche de luces falsas,

oropeles hechos de oscuridad:

¿Hacia dónde debo huir

que no sea mi propia alma.

el alma que queria ser bandera en el retorno (...)? 


\section{Aproximaciones a la obra ensayística de Roque Dalton}

Como muchos de los escritores de su generación, Roque es conocido como poeta alrededor del año 1956. Surge, en las aulas de la Universidad de El Salvador, un grupo de jóvenes poetas que, entre otras actividades, mantienen una página mensual en Diario Latino, gracias a la buena voluntad de Juan Felipe Toruño. Esta página - la del Círculo Literario Universitario- no se reduce a la publicación de los primeros versos del grupo. Es también un espacio para la polémica y en ella destaca mucho la labor de Roque.

Toda generación literaria se define por una serie de alïnidades que confluyen y dan identidad a un grupo de escritores: las fechas de nacimiento, las primeras publicaciones, pero, sobre todo, un ideario estético e ideológico en común. A la generación de Dalton la une la idea del compromiso del escritor, visto, en primer lugar, como la responsabilidad de escribir bien y, además, como una eticidad social y política. Sobre este último punto, es interesante la polémica que sostuvo Dalton con Antonio Gamero - poeta de la generación anterior a la suya-. En cl artículo Un concepto sobre poesía, publicado en 1956, Roque recrimina a Gamero la falta de coherencia entre su vida y su obra. Afirma:

Antonio Gamero no hace coincidir en la actualidad lo que escribe en sus versos con su manera de vivir en lo político y en lo social. Representa, con su manera de entregarse a la causa de un grupo divorciado de los más caros intereses del pueblo, la decadencia de un poeta que ha llegado al grado de bufón trágico, fabricante de discursos para coroneles y de editoriales políticos para la prensa oficial.

Al margen de la valoración que tengamos sobre Gamero, estas palabras son útiles para enterarnos de que la batalla de ideas que libra Roque se caracteriza desde un principio por los cuestionamientos de fondo. La de Dalton es una batalla en contra de la falsedad, pero también en contra de lo que él llamaría, en una entrevista hecha en Cuba, «la papanatería revolucionaria y no revolucionaria». Es indudable que su prolongada residencia en países como Checoslovaquia, Chile, México y Cuba le ayudó a ponerse en contacto con nuevas ideas y a nutrir sus planteamientos. Una buena parte de sus artículos y ensayos fue publicada precisamente en la isla, en revistas como Casa de las Américas. Lejos de ser Roque un poeta sumiso a una ortodoxia política o a un dirigismo cultural partidario, encontramos que él está constantemente haciendo cucstionamientos severos a la cultura dominante, a la poesía y a los escritores — revolucionarios o no- y a los actores políticos - tanto dentro como fuera del partido en el que militó-.

Así, por ejemplo, Dalton está convencido de que «el comunista que trata de hacer la revolución con un mal poema objetivamente hace contrarrevolución». Es decir, la literatura revolucionaria no puede, a sus ojos, darse el lujo de la mediocridad. Para Roque, un poeta, pero sobre todo, un poeta revolucionario, 
debe ser culto y conocedor de su oficio. A este respecto, afirma en Poesía y militancia en América Latina, trabajo publicado por Casa de las Américas en 1963: «Hay que desterrar esa concepción falsa, mecánica y dañina según la cual el poeta comprometido con su pueblo y con su tiempo es un individuo iracundo o excesivamente dolido que se pasa la vida diciendo, sin más ni más, que la burguesía es asquerosa, que lo más bello del mundo es una asamblea sindical y que el socialismo es un jardín de rosas dóciles bajo un sol especialmente tierno». En otras palabras, Dalton está diciendo que la opción política del autor por sí sola no es garantía de la buena calidad de su obra. Ello no deja de lado el hecho de que Dalton busca su sentido ético dentro de una opción política de izquierda.

Roque exige, además, del escritor, una actitud de apertura ante la realidad. Por ejemplo, en su ensayo sobre César Vallejo alaba la posición estética del poeta pcruano, en tanto la considera «abierta a todas las corrientes de avanzada de su tiempo», cosa que le permitió, a su juicio, captar «el espíritu de su época con un mćtodo realista y revolucionario, es decir, un método basado en su actitud humanista». Dicho de otra manera: para que la obra gane en profundidad, el escritor deberá abrir sus poros a las tendencias culturales, estéticas y de pensamiento de su época.

La obra en prosa de Dalton también incluye el comentario bibliográfico y los escritos políticos. Entre los primeros, podemos encontrar reseñas sobre libros de Julio Cortázar, Claribel Alegría, Haroldo Conti, Lisandro Chávez Alfaro, Roberto Fernández Retamar y Fayad Jamís, entre otros autores. Entre los escritos políticos destaca el ensayo ¿Revolución en la revolución? y la crítica de derecha, donde comenta los planteamientos de Régis Debray sobre la lucha armada en América Latina. La importancia coyuntural de ¿Revolución en la revolución? y la crítica de derecha, radica en que en este libro Dalton da sus opiniones sobre el tema de la lucha armada, que ocupa el centro del debate de la izquierda de su tiempo. En este texto se hacen explícitas sus diferencias con el «pensamiento oficial» de los partidos comunistas. Sería interesante analizar este texto a la luz del desarrollo histórico que media desde su año de publicación, 1970, hasta nuestros días.

¿Revolución en la revolución? y la crítica de derecha no solamente es un texto válido en términos documentales. También permite rastrear ciertas claves del pensamiento político de Dalton que merecen un tratamiento más riguroso. Una lectura muy superficial de este texto permite ver que el escritor salvadoreño está propugnando por un pensamiento marxista que se defina por su antidogmatismo. En uno de los párrafos, incita a la izquierda a una discusión abierta, sin concesiones, sobre los problemas políticos de Latinoamérica:

Es decir, vemos la labor de superación revolucionaria de ¿Revolución en la revolución? como una tarea conjunta, a nivel latinoamericano, de la cual se elininen la actitud de "perros-contra-gatos», la defensa de la intocabilidad 
eclesiástica de ciertos temas, de ciertas fijaciones supuestamente históricas J' de ciertos supuestos "derechos adquiridos». Creemos que el movimiento revolucionario de América Latina tiene ya los medios - nivel cultural, nivel de madurez política, etc. - para tomar a su cargo, conciente y responsablemente, tareas como ésta.

Se podría creer que Dalton, al optar por la lucha armada y al cuestionar la inacción de la izquierda tradicional, estaría renunciando al debate intelectual por entregarse a un activismo febril, irreflexivo. Nada más falso. Sobre el debate en derredor de la lucha armada, considera que éste es factible:

Siempre y cuando se ataque, desde el punto de partida, por lo menos dos posiciones igualmente suicidas: la de los que dicen que no hay ningún problema que discutir, que ya todas las respuestas están dadas desde hace tiempo y que toda incitación a la discusión es afán de contrabando ideológico izquierdizante; y la de los que dicen que hay que sacrificar toda inquietud teórica en aras de la "acción pura".

Como se ve, Dalton critica tanto a la izquierda divorciada de la acción revolucionaria, pero también a aquellos «revolucionarios» que desdeñan la labor teórica. Entiende que entre teoría y práctica revolucionaria no hay separación. Enuncia que entre ambas debe haber una interrelación mutua, un nutrirse mutuo. Sin quererlo, advirtió un mal que ha aquejado a la izquierda armada salvadoreña: ese desdén hacia el trabajo teórico y una actitud anti-intelectual. Las voces críticas, desde dentro, como la suya, han sido acalladas; las aportaciones intelectuales procedentes fuera de sus filas, condenadas a la indiferencia.

\section{Lo que falta}

Lo anterior ha intentado ser un recorrido muy sucinto sobre el pensamiento de Dalton. Ello nos lleva a la conclusión de que es necesario sacar sus textos dispersos de los anaqueles de las hemerotecas y llevarlos al público lector. Esta tarea implicaría ordenar sus ensayos literarios, sus reseñas bibliográficas y sus escritos políticos. Si bien ya existe, gracias a la labor de Rafael Lara Martínez, una nómina bibliográfica muy extensa y detallada de Roque - que incluye textos escritos y publicados en América Latina-, aún falta por conocer cuáles fueron los trabajos publicados durante su residencia en Checoslovaquia y otros lugares, por ejemplo.

Recordemos que, merced al desconocimiento, hemos tenido en el país una imagen distorsionada de Roque. Cierta izquierda lo ha presentado como un emblema partidario, prevaleciendo la difusión de su obra menos lograda estéticamente. Por otra parte, existe también el interés de la cultura oficial de hacerlo ver como una suerte de individuo esquizofrénico, en cuyo interior el poeta y el militante eran enemigos a muerte. Con ello no estoy negando de ninguna manera el hecho de que la personalidad de Roque era muy compleja y, como ocurre en esos casos, llena de contradicciones interiores. Admitir esto es muy diferente 
a hacer pasar a Dalton como un escritor esquizofrénico. Pero, para quitar toda duda al respecto, recordemos sus propias palabras:

Alguien definió al poeta como una persona que no vive normalmente si se le impide escribir. La construcción de este concepto es similar a la de un sentimiento que desde hace ya mucho tiempo siento arraigado en mi: el de la imposibilidad de ejercer la labor creadora fuera de las filas de la revolución. Si la revolución, o sea, la lucha de mi pueblo, mi partido, mi teoría revolucionaria, son los pilares fundamentales en que quiero basar mi vida y si considero la vida en toda su intensidad como el gran origen y el gran contenido de la poesía, ¿qué sentido tiene pensar en la creación cuando se abandonan los deberes de hombre y de militante?

Las manipulaciones políticas de la imagen del poeta, tanto de izquierda como de derecha, coinciden en presentárnoslo como un Dalton rígido, preparado quizá para habitar el mausoleo de las ideas y de la poesía. Parafraseando a Roque, hay que decir que «cualquiera puede hacer de los libros del joven Dalton un liviano puré de berenjenas, lo difícil es conservarlos como son, es decir, como alarmantes hormigueros». La publicación y discusión de la obra ensayística de Dalton posibilitará que conozcamos mejor su pensamiento, un pensamiento que sigue sintiéndose vivo y aclual.

\section{Nota}

1. Ver Una urgencia sin reposo en los huesos, de Luis Suardíaz, incluido en Valoración múltiple de Roque Dalton.

\section{Bibi.IOGRafía CONSULTADa}

- Dalton, Roque:

Libros:

- César Vallejo. Casa de las Américas, La Habana, 1983. Cortesía de Álvaro Menéndez Leal.

- En la humedad del secreto. Rafael Lara Martínez (editor). Dirección de Publicaciones de CONCULTURA, San Salvador, 1995.

- El intelectual y la sociedad. Siglo XXI Editores, México, 1969. Cortesía de Vladimir Baiza.

- La ventana en el rostro. Prólogo de Mauricio de la Selva. Ediciones de Andrea, Colección Los Presentes, México, 1961.

- Los testimonios. UCA Editores, San Salvador, 1996.

- Poemas clandestinos. EDUCA, San José de Costa Rica, 1987.

- ¿Revolución en la revolución? y la crítica de derecha. Casa de las Américas, La Habana, 1970.

- Taberna y orros lugares. UCA Editores, San Salvador, 1976 (prólogo de Italo López Vallecillos) y 1989 (prólogo de Eraclio Zepeda).

- Un libro rojo para Lenin. Editorial Nueva Nicaragua, Managua, 1986. 
Articulos:

- Un concepto sobre poesía. Diario Latino, febrero de 1956.

- Con Antonio Gamero: El poeta es una conducta. Diario Latino, 1956

- Poesía y militancia en América Latina. Casa de las Américas, Nos. 20-21, Año III, septiembre-diciembre de 1963. Cortesía de Luis Melgar Brizuela.

- Un caso de justicia histórica. La valoración de Anastasio Aquino. La Prensa Gráfica, lo. de julio de 1956.

- Testimonio de la Generación Comprometida. La Prensa Gráfica, 28 de abril de 1957.

- Literatura e intelectualidad: Dos concepciones. Casa de las Américas, No. 57. Año X, Nov-Dic 1969.

Varios autores. Recopilación de textos sobre Roque Dalton. Casa de las Américas, Serie Valoración Múltiple, La Habana, 1986. Cortesía de Gloria Anaya. 